\title{
ARTICLE
}

\section{Study on Microdosimetry for Boron Neutron Capture Therapy}

\author{
Tetsuya MUKAWA ${ }^{1, *}$, Tetsuo MATSUMOTO ${ }^{1}$ and Koji NIITA ${ }^{2}$ \\ ${ }^{1}$ Tokyo City University, 1-28-1 Tamazutsumi, Setagaya-ku, Tokyo, 158-8557, Japan \\ ${ }^{2}$ Research Organization for Information Science \& technology, 2-4 Shirakata, Tokai-mura, Naka-gun, Ibaraki, 319-1106 Japan
}

\begin{abstract}
A brain tumor, a malignant melanoma and recently a head-neck cancer have been treated by Boron Neutron Capture Therapy (BNCT). Neutrons from a research reactor have been used for BNCT. The therapeutic gain of BNCT depends on intercellular distributions of ${ }^{10} \mathrm{~B}$ and behavior of particles generated in the tumor cell. Two typical boron compounds of BSH (sodium borocaptate) and BPA (p-boronophenylalanine) have been used for BNCT. The BSH is especially accumulated around the cell membrane and the BPA around the cell nucleus. We have studied microdosimetry concerning on behavior of $\alpha$ and ${ }^{7} \mathrm{Li}$ particles by simulating a single and a multi-cell models, where the ${ }^{10} \mathrm{~B}$ distributions of BSH and BPA were assumed above accumulation conditions. The PHITS code developed in Japan Atomic Energy Agency was used for calculation of $\alpha$ and ${ }^{7} \mathrm{Li}$ particles with nuclear data library of ENDF/B-VI. The SPAR code including in the PHITS was also used for calculation of stopping power of these particles. We also evaluated LET values of $\alpha$ and ${ }^{7} \mathrm{Li}$ particles and dose distributions for BPA and BSH compounds by considering the influence from neighbor cells in a multi-cell model.
\end{abstract}

KEYWORDS: PHITS, microdosimetry, Boron neutron capture therapy, LET, dose distributuons

\section{Introduction}

A brain tumor, a malignant melanoma and recently a head-neck cancer have been treated by Boron Neutron Capture Therapy (BNCT). Neutrons from a research reactor have been used for BNCT. This therapy takes ${ }^{10} \mathrm{~B}$ to cancer cells which are destroyed by $\alpha$ and ${ }^{7} \mathrm{Li}$ particles from ${ }^{10} \mathrm{~B}(\mathrm{n}, \alpha)^{7} \mathrm{Li}$ reactions. The flight-paths (ranges) of these charged particles in tissue are around ten micrometers that are the same order of cell diameter. Therefore, cytocidal effect would be very high. If a ${ }^{10} \mathrm{~B}$ compound could be highly accumulated into the cancer cell, only the cancer cells would be broken as shown in Fig. 1.

Two typical boron compounds shown in Fig. 2, BSH (sodium borocaptate) and BPA (p-boronophenylalanine) are currently tested in clinical trial. One of the boron compounds, $\mathrm{BSH}$ will not take up into normal brain cells because of the BBB (Blood Brain Barrier) effect. Although BBB of tumor

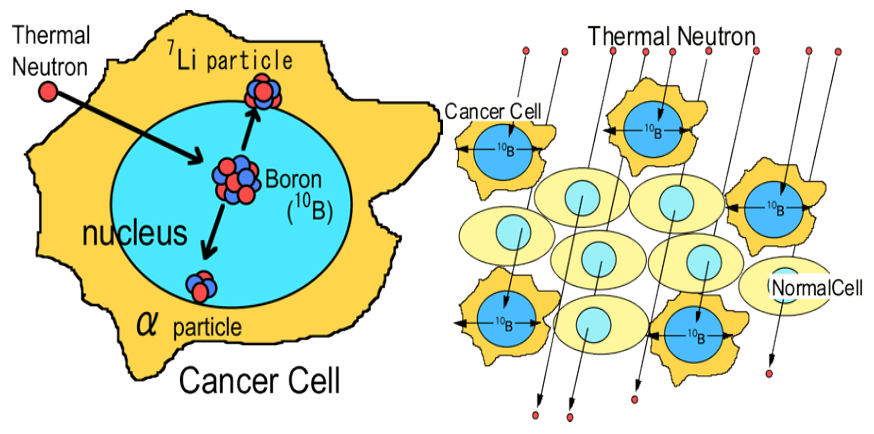

Fig. 1 Concepts of BNCT

*Corresponding author, E-mail: telururu@hotmail.co.jp

(C) 2011 Atomic Energy Society of Japan, All Rights Reserved.
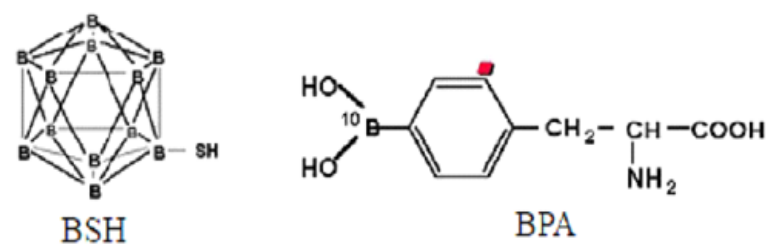

Fig. 2 Two kinds of boron compounds used for $\mathrm{BNCT}^{1)}$

cell are damaged so that $\mathrm{BSH}$ is able to accumulate in tumor cells, especially around the cell membrane. The other boron compounds, BPA has inherent accumulation in malignant melanoma because its chemical structure resembles tyrosine and DOPA (dihydroxy-phenylalanine) which is the precursor of the melanin metabolism. In addition, BPA is an amino acid analogue thus it is taken up by the cells that amino acid metabolism is active and pass through the BBB barrier. Also BPA especially accumulates around the cell nucleaus. ${ }^{1)}$

From the above features of two boron compounds, distribution of boron in the cells would be different. The cytocidal effect could be specialized by the distributions of $\alpha$ and ${ }^{7} \mathrm{Li}$ particles in the cells.

In this paper, we evaluated the values of dose and LET respectively in the cells, by clarifying the behavior of $\alpha$ and ${ }^{7} \mathrm{Li}$ particles produced from the $\left.{ }^{10} \mathrm{~B}(\mathrm{n}, \alpha)\right)^{7} \mathrm{Li}$ reactions.

\section{Calculation Method}

\section{Calculation Code}

The PHITS (Particle and Heavy Ions Transport code system $)^{2,3)}$ developed in Japan Atomic Energy Agency was used for the calculation of $\alpha$ and ${ }^{7} \mathrm{Li}$ particles with nuclear 


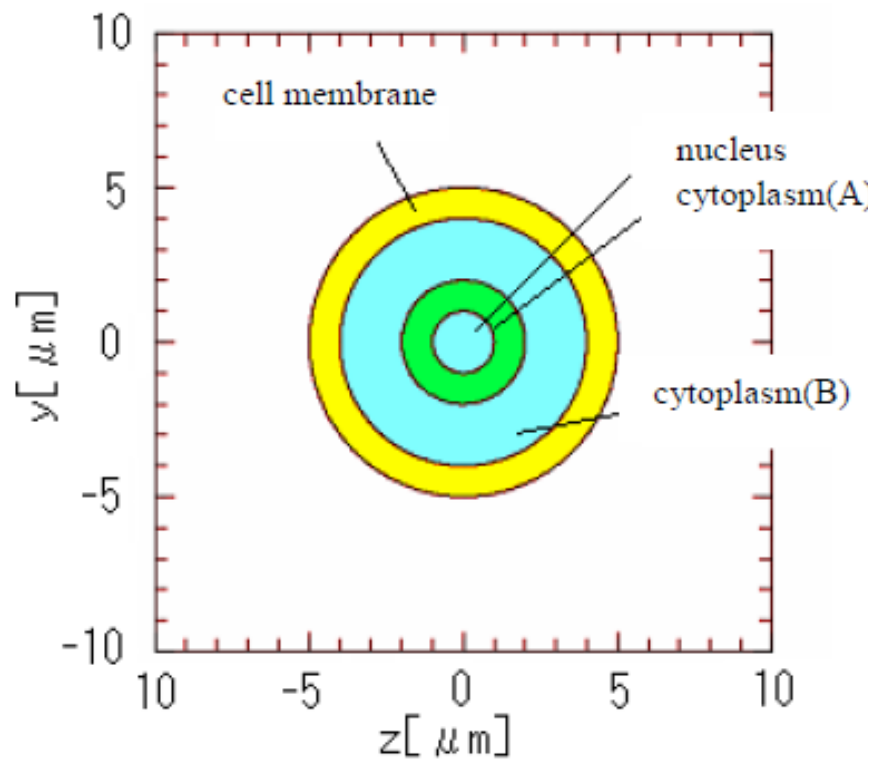

Fig. 3 Single cell model

Table 1 Thickness of area in cell

\begin{tabular}{ccccc}
\hline Area & nucleus & cytoplasm(A) & cytoplasm(B) & cell membrane \\
\hline thickness(um) & 1.0 & 1.0 & 2.0 & 1.0 \\
\hline
\end{tabular}

data library of ENDF/B-VI. ${ }^{4)}$ The SPAR code ${ }^{5)}$ including in the PHITS was also used for the calculation of stopping power of these particles.

\section{Single Cell Model}

A single cell model was used to simplify the calculation of the behavior of particles. The area (thickness) in the cell was set as shown in Table 1 corresponding to the region in Fig. 3. To clarify distributions of $\alpha$ and ${ }^{7} \mathrm{Li}$ particles a single-cell model is first examined. The compositions of a cell referred ICRU reports $44 .{ }^{6)}$ It was assumed that ${ }^{10} \mathrm{~B}$ was accumulated in the cell membrane for $\mathrm{BSH}$ and in the cytoplasm(A) for BPA. The ${ }^{10} \mathrm{~B}$ concentration in a cell is $24 \mathrm{ppm}$ for both compounds. The thermal neutron fluence of $5 \times 10^{12} \mathrm{n} / \mathrm{cm}^{2}$ was distributed entirely in the cell. The number of particles generated, ranges, Lineal Energy Transfer (LET) and dose-distributions were calculated.

\section{Multi-Cell Model}

The multi-cell model consisted of 7 cells was applied to evaluate the influence from the neighbor cells as shown in Fig. 4.

The dose distributions and LET values at center of cell for the multi-cell model have been calculated. The ${ }^{10} \mathrm{~B}$ concentration of each cell in the multi-cell model was the same accumulation as that of a single-cell model.

\section{Results and Discussion}

\section{Single Cell Model}

(1) Number of Particles Generated

Equation (1) shows a typical ${ }^{10} \mathrm{~B}(\mathrm{n}, \alpha)^{7} \mathrm{Li}$ reactions used

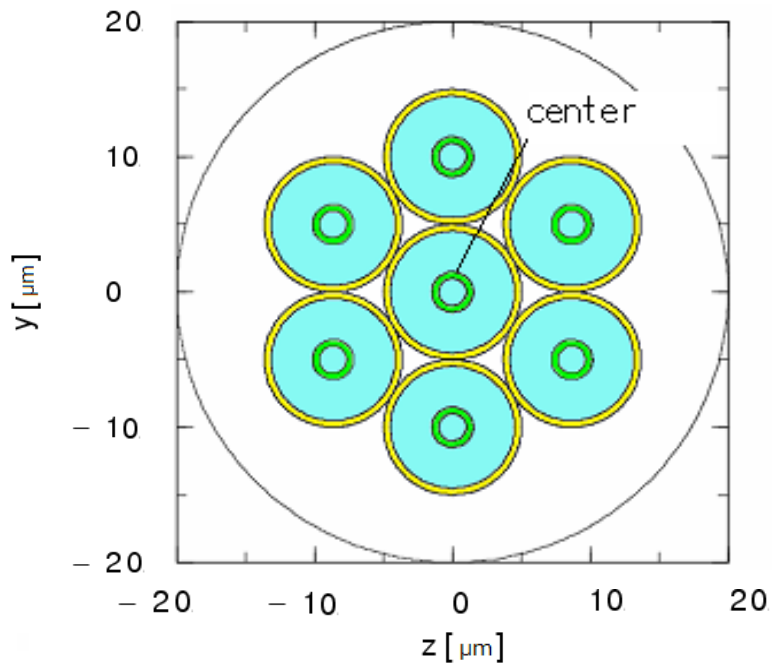

Fig. 4 Multi-cell model

Table 2 Numbers of $\alpha$ and ${ }^{7} \mathrm{Li}$ particles

\begin{tabular}{|c|c|c|c|}
\hline \multicolumn{2}{|c|}{ energy } & numbers & reaction ratio \\
\hline$\alpha$ & $1.5 \mathrm{MeV}$ & 13.8 & $93.6 \%$ \\
\hline & $1.8 \mathrm{MeV}$ & 0.9 & $6.4 \%$ \\
\hline${ }^{7} \mathrm{Li}$ & $0.8 \mathrm{MeV}$ & 13.8 & $93.6 \%$ \\
\hline & $1.0 \mathrm{MeV}$ & 0.9 & $6.4 \%$ \\
\hline
\end{tabular}

for BNCT. The numbers of particles calculated by the PHITS code are shown in Table 2 when thermal neutron fluence of $5 \times 10^{12} \mathrm{n} / \mathrm{cm}^{2}$ was irradiated at a cell. The total number of $\alpha$ and ${ }^{7} \mathrm{Li}$ particles was 14.7 for both BSH and $\mathrm{BSH}$ compounds which was equal to the value deduced from Eq. (2).

$$
\begin{array}{rl}
{ }^{10} \mathrm{~B}+\mathrm{n} & \rightarrow{ }^{7} \mathrm{Li}+\alpha+2.79 \mathrm{MeV}(6.3 \%) \\
& \rightarrow{ }^{7} \mathrm{Li}^{*}+\alpha+2.31 \mathrm{MeV}(93.7 \%) \\
{ }^{7} & \mathrm{Li}+\gamma+0.478 \mathrm{MeV} \\
N_{B} \times \sigma_{c a p} & \times \Phi_{t h}=R,
\end{array}
$$

where $N_{B}$ :atomic number density of ${ }^{10} B$, $\sigma_{\text {cap }}$ :cross section of ${ }^{10} \mathrm{~B}(\mathrm{n}, \mathrm{a})^{7} \mathrm{Li}$ reaction, $\Phi_{t h}:$ thermal neutron fluence,

$R$ : number of reaction.

Figure 5 shows calculated spectrum of $\alpha$ and Li particles from the ${ }^{10} \mathrm{~B}(\mathrm{n}, \alpha){ }^{7} \mathrm{Li}$ reactions. The energies of $\alpha$ and ${ }^{7} \mathrm{Li}$ particles can be recognized according to the reaction ratio as shown in Table 2. The gamma-rays of $0.48 \mathrm{MeV}$ and $2.2 \mathrm{MeV}$ are also found, which are from ${ }^{7} \mathrm{Li}^{*}$ particle and ${ }^{1} \mathrm{H}(\mathrm{n}, \gamma)^{2} \mathrm{D}$ reactions, respectively. The proton of $0.63 \mathrm{MeV}$ from ${ }^{14} \mathrm{~N}(\mathrm{n}, \mathrm{p}){ }^{14} \mathrm{C}$ reactions are slightly recognized.

(2) Energy Deposit and LET Values

Figure 6 shows energy deposit distributions obtained for $\alpha$ and ${ }^{7} \mathrm{Li}$ particles. The ${ }^{10} \mathrm{~B}$ compounds have been accumulated in $0-1 \mu \mathrm{m}$ area. The $\alpha$ and ${ }^{7} \mathrm{Li}$ particles lost their energies at $9 \mu \mathrm{m}$ and $4 \mu \mathrm{m}$, respectively. 


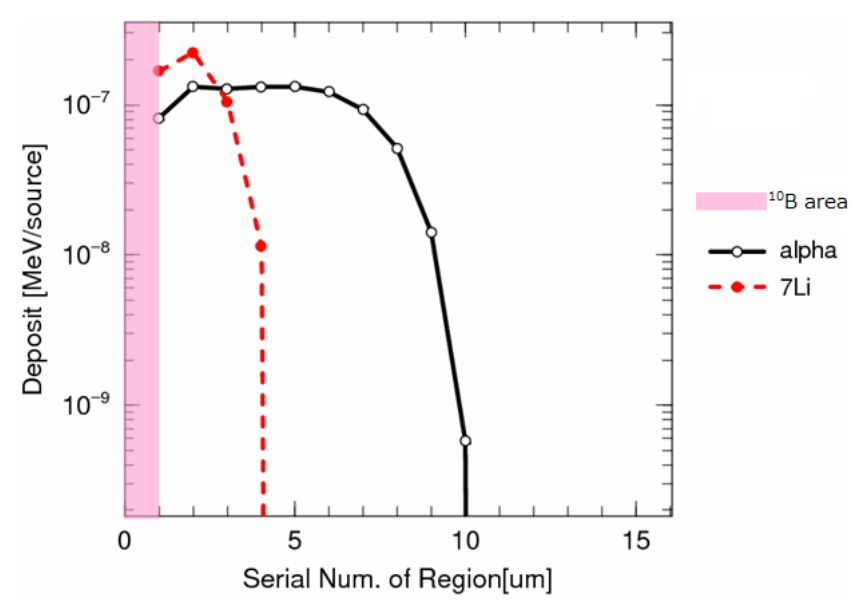

Fig. 6 Ranges of $\alpha$ and ${ }^{7} \mathrm{Li}$ particles in tissue

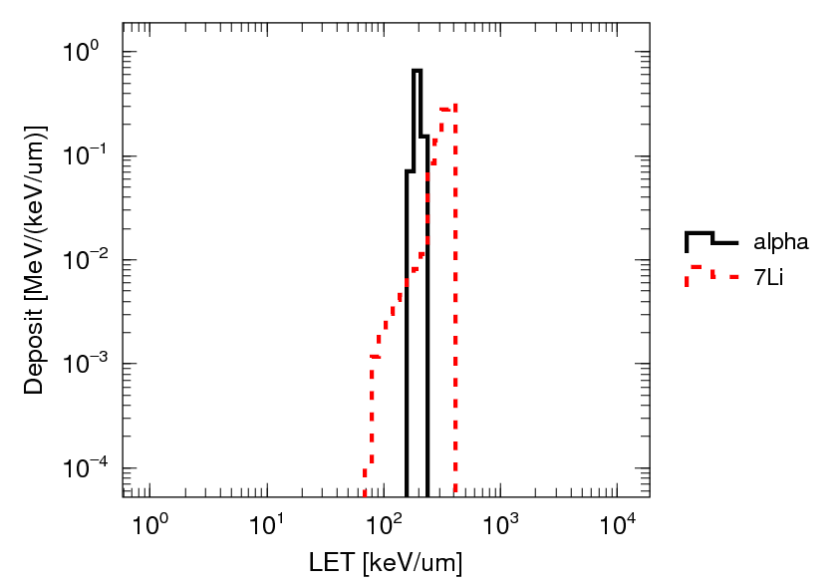

Fig. 7 Relations between energy deposit and LET from $1 \mu \mathrm{m}$ to $2 \mu \mathrm{m}$

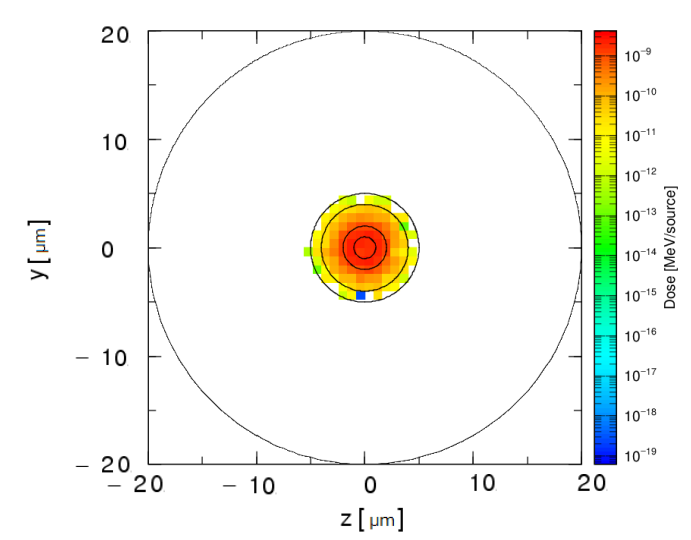

Fig. 8 Dose distribution of $\alpha$ particle in a single-cell model for BPA

Figure 7 shows relations between energy deposit and LET values at the distance from $1 \mu \mathrm{m}$ to $2 \mu \mathrm{m}$. The $\alpha$ and ${ }^{7} \mathrm{Li}$ particles were originally emitted from the ${ }^{10} \mathrm{~B}$ accumulation area, such as cytoplasm(A) for BPA and cell membrane for BSH. The LET values of $\alpha$ and ${ }^{7} \mathrm{Li}$ particles were 200 and $400 \mathrm{keV} / \mu \mathrm{m}$, in 1-2 $\mu \mathrm{m}$ range respectively.

The dose-LET distributions from ${ }^{7} \mathrm{Li}$ cannot be observed at the distance greater than $3 \mu \mathrm{m}$, because of the shorter

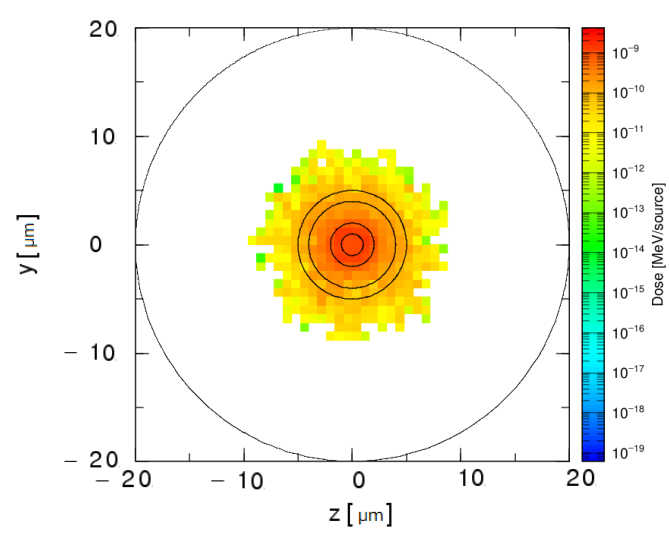

Fig. 9 Dose distribution of ${ }^{7} \mathrm{Li}$ particle in a single-cell model for BPA

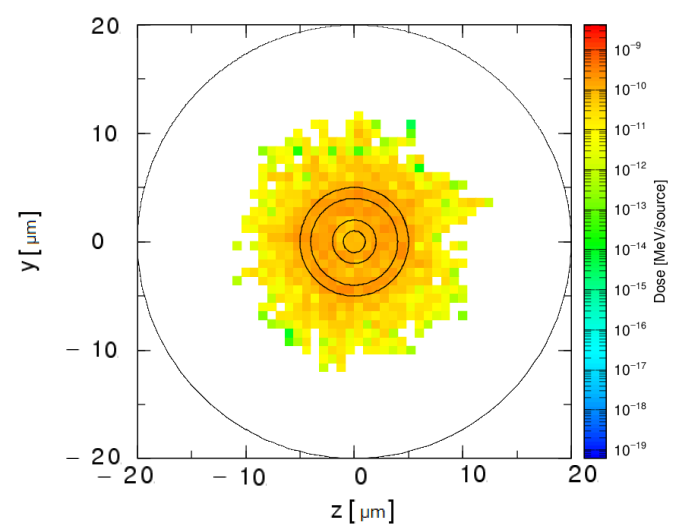

Fig. 10 Dose distribution of $\alpha$ particle in a single-cell model for BSH

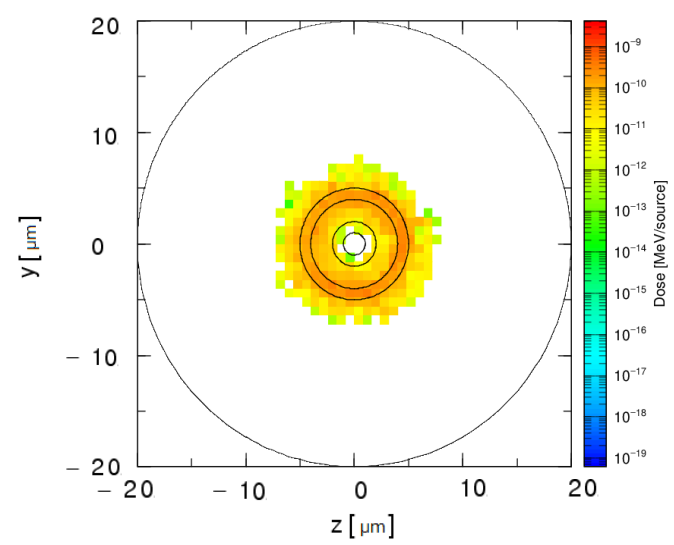

Fig. 11 Dose distribution of ${ }^{7} \mathrm{Li}$ particle in a single-cell model for BSH

range of the particle.

(3) Dose Distribution

Figures 8-11 illustrate $\alpha$ and ${ }^{7} \mathrm{Li}$ particles produced in a single-cell model, for BPA and BSH compounds respectively. It is clear that a range of $\alpha$ particles is larger than that of ${ }^{7} \mathrm{Li}$ particles in both compounds. We can see large number of these particles outside cell for a BSH model. The hit numbers in nucleus for BSH model are very small. 


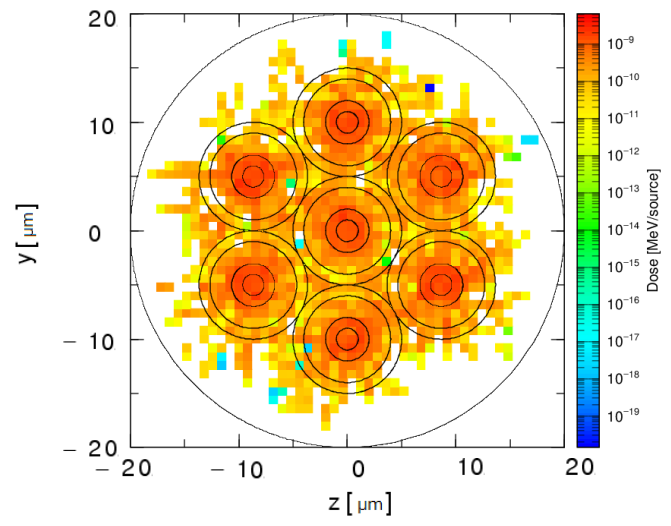

Fig. 12 Dose distribution of $\alpha$ particle in a multi-cell model for BPA

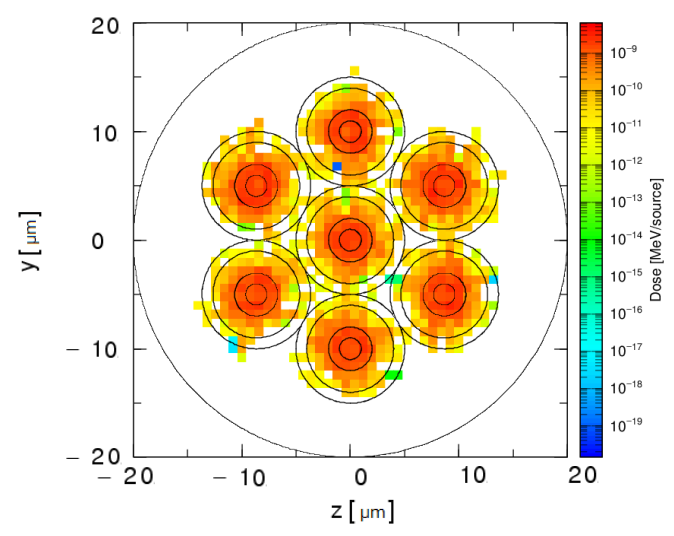

Fig. 13 Dose distribution of ${ }^{7} \mathrm{Li}$ particle in a multi-cell model for BPA

Table 3 Dose by $\alpha$ and ${ }^{7} \mathrm{Li}$ particles in a single-cell model [Gy]

\begin{tabular}{|c|c|c|c|c|c|c|}
\hline & area & nucleus & cytoplasm(A) & cytoplasm(B) & cell membrane & cell average \\
\hline BPA & (total) & $24.1 \pm 0.9$ & $27.3 \pm 0.4$ & $4.3 \pm 0.1$ & $1.2 \pm 0.0$ & $4.2 \pm 0.0$ \\
\hline & $\alpha$ & $8.9 \pm 0.3$ & $10.1 \pm 0.1$ & $2.5 \pm 0.1$ & $0.1 \pm 0.0$ & $2.3 \pm 0.0$ \\
\hline & ${ }^{7} \mathrm{Li}$ & $15.2 \pm 0.6$ & $17.2 \pm 0.3$ & $1.8 \pm 0.0$ & $0.1 \pm 0.0$ & $1.9 \pm 0.0$ \\
\hline $\mathrm{BSH}$ & (total) & $0.9 \pm 0.1$ & $1.1 \pm 0.1$ & $2.1 \pm 0.0$ & $3.7 \pm 0.0$ & $2.8 \pm 0.0$ \\
\hline & $\alpha$ & $0.9 \pm 0.1$ & $1.0 \pm 0.1$ & $1.3 \pm 0.0$ & $1.7 \pm 0.0$ & $1.4 \pm 0.0$ \\
\hline & ${ }^{7} \mathrm{Li}$ & 0 & $0.1 \pm 0.0$ & $0.8 \pm 0.0$ & $2.0 \pm 0.0$ & $1.3 \pm 0.0$ \\
\hline
\end{tabular}

Table 3 shows the dose distributions at each area in a cell obtained for BPA and BSH compounds. The doses in the cell nucleus are 24.1 Gy for BPA and $0.9 \mathrm{~Gy}$ for BSH. The average doses are 4.2 Gy for BPA and 2.8 Gy for BSH. The $\mathrm{BSH}$ dose is about two times smaller than BPA dose because $\alpha$ particles in a BSH model runs away to outside.

\section{Multi Cell Model}

Figures 12-15 illustrate $\alpha$ and ${ }^{7} \mathrm{Li}$ particles produced in a multi-cell model, for BPA and BSH compounds, respectively. It is found that the dose distributions in a multi-cell model are similar to these of a single-cell model for BPA and BSH, even though the influence from neighbor cells is added. Table 4 shows the dose distributions at each area in a center of cell for the BPA and PSH compounds. The average doses in a center cell were 4.6 Gy for BPA and

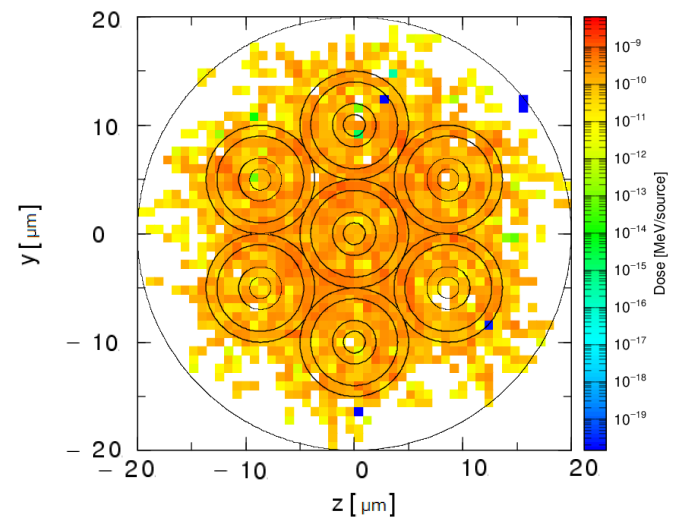

Fig. 14 Dose distribution of $\alpha$ particle in a multi-cell model for BSH

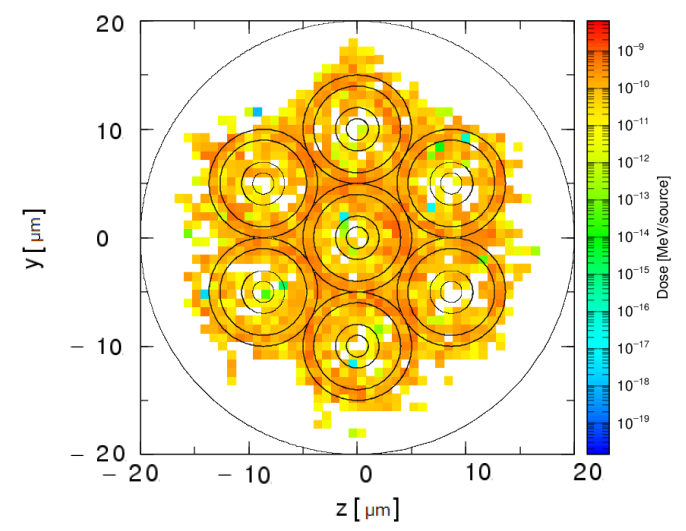

Fig. 15 Dose distribution of ${ }^{7} \mathrm{Li}$ particle in a multi-cell model for BSH

Table 4 Dose by $\alpha$ and ${ }^{7} \mathrm{Li}$ particles in a multi-cell model [Gy]

\begin{tabular}{|c|c|c|c|c|c|c|}
\hline & area & nucleus & cytoplasm(A) & cytoplasm(B) & cell membrane & cell average \\
\hline BPA & (total) & $25.6 \pm 1.3$ & $27.8 \pm 0.6$ & $4.6 \pm 0.1$ & $1.6 \pm 0.1$ & $4.6 \pm 0.1$ \\
\hline & $\alpha$ & $10.0 \pm 0.5$ & $10.7 \pm 0.2$ & $2.7 \pm 0.1$ & $1.5 \pm 0.1$ & $2.6 \pm 0.1$ \\
\hline & ${ }^{7} \mathrm{Li}$ & $15.6 \pm 0.8$ & $17.2 \pm 0.3$ & $1.9 \pm 0.0$ & $0.1 \pm 0.1$ & $2.0 \pm 0.1$ \\
\hline $\mathrm{BSH}$ & (total) & $1.0 \pm 0.1$ & $1.5 \pm 0.2$ & $2.6 \pm 0.1$ & $4.6 \pm 0.1$ & $3.5 \pm 0.2$ \\
\hline & $\alpha$ & $1.0 \pm 0.1$ & $1.4 \pm 0.1$ & $1.8 \pm 0.1$ & $2.3 \pm 0.1$ & $2.0 \pm 0.1$ \\
\hline & ${ }^{7} \mathrm{Li}$ & 0.0 & $0.1 \pm 0.1$ & $0.9 \pm 0.1$ & $2.3 \pm 0.1$ & $1.5 \pm 0.1$ \\
\hline
\end{tabular}

3.5 Gy for BSH. The average dose in a multi-cell model was higher than a single-cell model for both compounds because $\alpha$ and ${ }^{7} \mathrm{Li}$ particles from neighbor cells influenced to other cells especially for BSH. The doses in the nucleus were 25.6 Gy for BPA and 1.0 Gy for BSH. The $\alpha$ particles gave $20 \%$ and $24 \%$ dose enhancement to cytoplasm and cell membranes doses, respectively, because of relatively longer flight-path than ${ }^{7} \mathrm{Li}$ particles.

\section{Conclusion}

We have studied on microdosimetry for boron neutron capture therapy. The boron concentrations in tumor were assumed depending on the boron distribution of BPA and $\mathrm{BSH}$ compounds. This study clearly shows as followings.

We calculated the number of $\alpha$ and ${ }^{7} \mathrm{Li}$ particles, ranges, 
LET values and dose distributions by using PHITS code. The number of $\alpha$ and ${ }^{7} \mathrm{Li}$ particles produced in a tumor cell containing $24 \mathrm{ppm}$ of ${ }^{10} \mathrm{~B}$ were 14.7 respectively, when irradiating thermal neutron fluence of $5 \times 10^{12} \mathrm{n} / \mathrm{cm}^{2}$. The flight-paths of $\alpha$ and ${ }^{7} \mathrm{Li}$ particles were $9 \mu \mathrm{m}$ and $4 \mu \mathrm{m}$ respectively. The LET values of $\alpha$ and ${ }^{7} \mathrm{Li}$ particles were $200 \mathrm{keV} / \mu \mathrm{m}$ and $400 \mathrm{keV} / \mu \mathrm{m}$, respectively. The average doses were $4.2 \mathrm{~Gy}$ for BPA and $2.8 \mathrm{~Gy}$ for $\mathrm{BSH}$ in a single-cell model. Those doses increased to 4.6 Gy for BPA and $3.5 \mathrm{~Gy}$ in a multi-cell model by influence from the neighbor cells. From these results we understood the behavior of $\alpha$ and ${ }^{7} \mathrm{Li}$ particles in a cell, and found that the average dose in a cell could increase when ${ }^{10} \mathrm{~B}$ accumulated near the cell nucleus like a BPA compound. To clarify the BNCT mechanism in details by microdosimetry, it is necessary to calculate the dose by using a three dimensional multi-cell model under the accurate intracellular ${ }^{10} \mathrm{~B}$ distributions. The experiments of cell survival should be also examined.

\section{References}

1) K. Amamiya, "Soft X-ray imaging using CR-39 plastics with AFM readout," Nucl. Instr. Meth. Phys. Res., B187, 361-366 (2002).

2) K. Niita, T. Sato, H. Iwase, H. Nose, H. Nakashima, L. Sihver, "PHITS-a particle and heavy ion transport code system," Radiat. Meas., 41, 1080-1090 (2006).

3) N. Koji, "Event generator mode introduced into PHITS," RIST news, 45 (2008), [in Japanese].

4) P. F. Rose, Cross Section Evaluation Working Group, ENDF/B-VI Summary Documentation, BNL-NCS-17541 (ENDF-201), National Nuclear Data Center, Brookhaven National Laboratory (BNL) (1991).

5) T. W. Armstrong, K. C. Chandler, SPAR, A FORTRAN Program for Computing Stopping Powers and Ranges for Muons, Charged Pions, Protons, and Heavy Ions, ORNL-4869, Oak Ridge National Laboratory (ORNL) (1973).

6) ICRU, Tissue Substitutes in Radiation Dosimetry and Measurement, International Commission on Radiation Units and Measurements, Report44, Bethesda, MD (1989) 